\title{
Introduction to the Next Chapters: Two Kantian Ideals Of Autonomy
}

In the following chapters, I will consider two Kantian ideals of autonomy. By doing this, it is not primarily my aim to provide a comprehensive view of Kant's view of autonomy or of his moral philosophy. Rather, I shall deal with the questions 'To what extent is this view Kant's own view?' or 'What did Kant really say?' only in so far as this assists my search for an alternative to the extended ideal of autonomy which is able to deal with its problems, drawing on Kant and Kantian material.

The first view I will consider is Hill's Kantian ideal of autonomy, since it may provide a metaphysically economical solution to the problem of infinite regress and therefore avoid Problem One of the extended ideal (that of a costly metaphysics).

The second view I will consider is based on my own construction of the ideal of autonomy to be found in Kant's Groundwork and Religion within the Limits of Reason Alone, aided by Allison's interpretation. I will show that Kant was well aware of the problems I have identified in my account of the 'extended' ideal of autonomy and made a serious attempt to deal with them. 